\title{
A new liquid phase microextraction method-based reverse micelle for analysis of dexketoprofen in human plasma by HPLC-DAD
}

\author{
Dönay Yuvali ${ }^{1}$, Erkan Yilmaz ${ }^{1,2,3}$ and Ibrahim Narin ${ }^{1 *}$ (D)
}

\begin{abstract}
A new liquid phase microextraction method was developed by used reverse micelle-based coacervates as microextraction agents for the separation of dexketoprofen (DKT) from human plasma before its determination by high-performance liquid chromatography with photodiode-array detection (HPLC-DAD). The change in the concentration of dexketoprofen in the plasma of the male and female patients was successfully monitored by using this method. The proposed method involves the use of reverse micelles of decanoic acid (DA) are dispersed in tetrahydrofuran (THF) and aqueous system. After addition of the DA and THF to the aqueous sample phase, the formation of micelles of nano and molecular size was observed in an ultrasonic bath. The solution was centrifuged, and the DKT extracted into the DA phase was analyzed by HPLC-DAD. Some analytical parameters that important in the developed procedure were examined in detail. The limit of detection (LOD), the limit of quantification ( $L O Q$ ), the intraday, and inter day relative standard deviation (RSD, \%) of the developed method in the plasma sample were found to be $12.8 \mathrm{ng} \mathrm{mL}^{-1}, 38.8 \mathrm{ng} \mathrm{mL}^{-1}, 1.7$ and $3.9 \%$, respectively. Additional/recovery studies were performed in plasma samples with proposed method, and quantitative recoveries were obtained in the range of 97-100\%. The developed microextraction method was applied to human plasma that taken from volunteer patients for the determination of DKT.
\end{abstract}

Keywords: Dexketoprofen, Determination, HPLC, Reverse micelle-based coacervates, Microextraction, Plasma

\section{Introduction}

Non-steroidal anti-inflammatory drugs (NSAIDs) are widely used by the adult person who has headache, pain, cold, rheumatoid arthritis, osteoarthritis, acute gouty arthritis, and dysmenorrhea. Dexketoprofen trometamol is a water-soluble salt of the $\mathrm{S}(+)$ enantiomer of the ketoprofen (Wongrakpanich et al. 2018). The most important adverse effect of NSAID use are gastrointestinal complications, including ulcers and bleeding, and renovascular/cardiovascular reactions with fluid retention

\footnotetext{
* Correspondence: narin@erciyes.edu.tr

${ }^{1}$ Faculty of Pharmacy, Deparment of Analytical Chemistry, Erciyes University, Kayseri 38039, Turkey

Full list of author information is available at the end of the article
}

and in some cases, deteriorated renal function, resulting in elevated blood pressure and an increased risk for heart failure (Buffum and Buffum 2000; Miranda et al. 2016). The recommended analgesic and anti-inflammatory dose of dexketoprofen is 12.5 to $50.0 \mathrm{mg}$. The results of preclinical studies suggest that lower dosages of the dexketoprofen may be active. The quantification of dexketoprofen in human plasma is important for regulate the plasma concentration of the drug and minimize the side effects (Esparza-Villalpando et al. 2018).

A lot of analytical methods are reported for quantitative analysis of dexketoprofen in biological matrix and pharmaceutical dosage such as liquid chromatography-tandem mass spectrometry (Tettey-Amlalo and Kanfer 2009; 
Wille et al. 2010), high-performance liquid chromatography (Marco-Urrea et al. 2010; Bhusari and Dhaneshwar 2011; Dvořák et al. 2004; Abolu-Enein et al. 2003), and spectrophotometric methods (Mabrouk et al. 2014; Choudhari et al. 2012).

The sample preparation for dexketoprofen usually achieved through liquid-liquid extraction (LLE) and solid phase extraction (SPE) (Moein et al. 2017). The conventional sample extraction techniques such as LLE and SPE have some important disadvantages that LLE require high-volume toxic solvent and SPE need to have expensive and specific sorbent for extraction of analytes. On the other hand, these techniques take a long time for extraction (Kole et al. 2011; Vaghela et al. 2016).

Green analytical chemistry extraction techniques and sample preparation are the most important issues in the last decade. The main objectives of green analytical chemistry are assessment in the use of chemical and toxic use, minimize time and energy consumption, reduce wastage of sample preparation, and improve safety in the laboratory.

The new extraction methods for main targets of green chemistry have developed microextraction methods involving liquid phase microextraction (LPME) and solid phase microextraction method (Armenta et al. 2008; Haq et al. 2017). LPME methods are more attractive, and some advantages are simplicity, sensitivity, rapidly, and environmentally friendly. The discovering of new non-toxic solvents has increased LPME methods for sample preparation (Mohamed 2015).

Reducing organic solvent consumption has encouraged the development of more environmentally friendly sample treatments in analytical processes. Reverse micellebased coacervates are nanostructured liquids produced in colloidal solutions of amphiphilic compounds by spontaneous, sequential self-assembly, and coacervation (Ballesteros-Gómez et al. 2010). Reverse micelle-based coacervates have intrinsic properties that make them very attractive for extraction processes. These properties were derived from the amphiphilic character of the molecules making them and their high concentration. Thus, nanostructures in the reverse micelle-based coacervates have regions of different polarity that offer several types of interactions for solutes and consequently mixed mechanisms for their solubilization (Feizi et al. 2017; López-Jiménez et al. 2014). These solvents have different interactions with this kind of structure. Reverse micellebased coacervates involve both dispersion and hydrogen bonding interactions. This nanostructured liquid provides an excellent reaction media for the extraction process. Due to the fact that reverse micelle-based coacervates have excellent properties, their usage in liquid phase-based microextraction techniques for organic and inorganic analytes determinations is increasing day by day (Ballesteros-Gómez and Rubio 2012).
The aim of this research was to perform a suitable liquid phase microextraction method by using decanoic acid as reverse micelle-based coacervates that is rapid, easy, safe, and low-cost for separation of dexketoprofen from human plasma prior to HPLC-DAD analysis.

\section{Experimental \\ Instruments and reagents}

The chromatographic separation and determination was carried out by Agilent 1200 series high-performance liquid chromatograph equipped with a diode array detector. A pH meter (Inolab, WTW pH720, Germany, Weilheim), an ultrasonic water bath (Bandelin Sonorex, Germany, Berlin) was used to emulsify the solutions, which improve the extraction efficiency. Centrifugal device (Nüve, NF 800, Turkey, Ankara) was used to accelerate the separation of extraction phases. The images of nano and molecular micelles were obtained by scanning electron microscope (SEM) (Zeiss Evo LS10, Jane, Germany) at Erciyes University Nanotechnology Application and Research Center.

For chromatographic analysis of dexketoprofen, we applied the modified method of Barbanoj et al. for determination of dexketoprofen from plasma (Barbanoj et al. 1998). A C18 chromatography column $(250 \times 4.6 \mathrm{~mm}, 5$ $\mu \mathrm{m}, \mathrm{HiChroma}, \mathrm{UK})$ was used for the separations. The mobile phase were a mix of acetonitrile:phosphate buffer solution (pH 3.0, $25 \mathrm{mM}$, phosphoric acid: sodium phosphate), $(70: 30 \mathrm{v} / \mathrm{v})$. The flow rate is $0.7 \mathrm{~mL} / \mathrm{min}$. The sample injection volume was $20 \mu \mathrm{L}$ and determination wavelength was $256 \mathrm{~nm}$.

DA and THF were purchased from Sigma-Aldrich (Germany, Steinheim). Dexketoprofen (purity > 99.5\%) was donated from Deva drug company (Turkey, Istanbul). Stock solution of dexketoprofen prepared concentration of $100 \mu \mathrm{g} \mathrm{mL}{ }^{-1}$ in methanol and stored at 4 ${ }^{\circ} \mathrm{C}$. The HPLC grade acetonitrile was purchased from Merck (Germany, Darmstadt). All aqua solutions were prepared by using deionized water $\left(15 \mathrm{M} \Omega \mathrm{cm}^{-1}\right.$, resistivity) obtained from Millipore Elix 5.

\section{Coacervative microextraction of dexketoprofen}

Schematical diagram of the developed liquid phase microextraction (LPME) procedure is shown in Fig. 1. In this method, $10 \mathrm{~mL}$ of aqueous sample solution containing different concentrations of dexketoprofen, $1 \mathrm{~mL}$ of phosphate buffer (pH 3.0, $100 \mathrm{mM}$ ), and $200 \mathrm{mg}$ Decanoic acid (as reverse micelle coacervates agent) were placed in $10 \mathrm{~mL}$ of centrifuge tubes. Then, $600 \mu \mathrm{L}$ of THF was added into the homogeneous solution leading to aggregation of decanoic acid molecules and consequently a turbid solution. In order to entirely disperse the aggregated decanoic acid droplets into aqueous phase, the turbid solution was sonicated for $7 \mathrm{~min}$ in ultrasonic bath. At this 


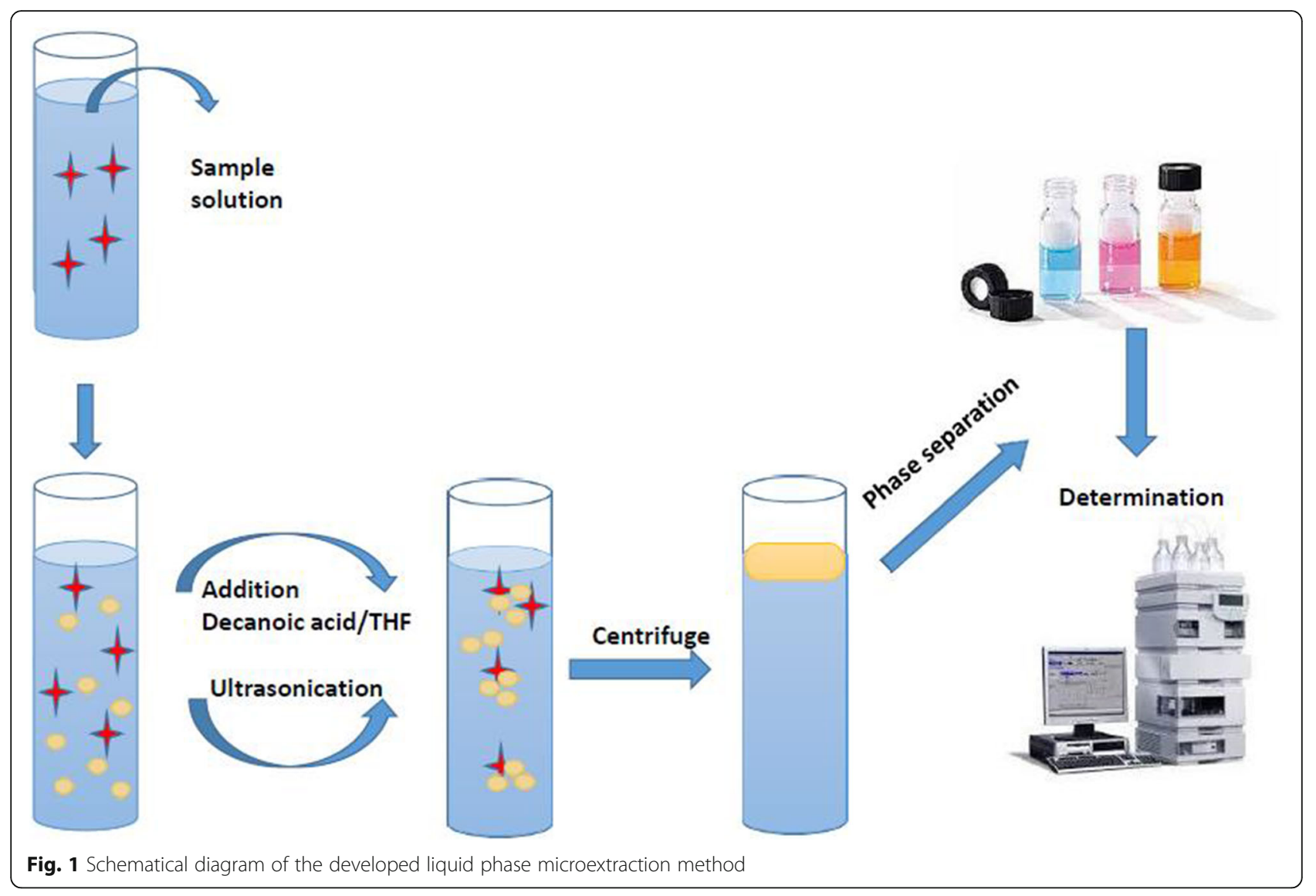

step, the aggregated reverse micelle droplets progressively broke into nano- or micro-sized reverse micelle coacervates since ultrasonic wave cause transient cavitation near the interface of reverse micelle droplets. After centrifuging for $10 \mathrm{~min}$ at $4000 \mathrm{rpm}$, two clear phases consist of aqueous phase and reverse micelle rich phase were observed and the lower aqueous phase was withdrawn through a micro-syringe. The about $200 \mu \mathrm{L}$ of the reverse micelle rich phase was obtained and diluted acetonitrile to $500 \mu \mathrm{L}$ and $20 \mu \mathrm{L}$ of this solution was injected into the HPLCDAD system for dexketoprofen analysis. The same procedures explained in above sections were applied to plasma samples taken from male and female patients. The calibration curve of plasma and aqueous model samples were determined based on peak areas of dexketoprofen, and the enrichment factors were calculated. The results of the plasma sample analysis were quantified from the calibration curve and multiplied by the enrichment factor that 2 for plasma samples.

\section{Pretreatment of plasma samples}

Blood samples were obtained from volunteer patients. Firstly, before using medicine and after taking dexketoprofen was taken blood samples. Samples centrifuged at $4000 \mathrm{rpm} 25 \mathrm{~min}$ for separate plasma and other component of blood. Plasma samples (aprox. $6 \mathrm{~mL}$ ) were stored at $-20{ }^{\circ} \mathrm{C}$ before extraction procedure was developed. The most important feature of plasma and serum is that it contains a large amount of protein. There is a strong affinity among proteins and drugs. Dexketoprofen and other analgesic drugs are strongly bounding to plasma proteins, particularly albumin. Therefore, the problem is physiologically destroying the binding of the drug to the protein and extracting the total drug for analysis. The simplest and oldest method is to precipitate proteins and isolate the filtrate (supernatant). It is denatured by protein precipitation and drug binding ability is impaired. Thus, the total drug is released into the filtrate. It is recommended that at least twice the volume of methanol, ethanol, or acetonitrile is required to precipitate all plasma proteins (Xue et al. 2006).

Hence, $1.0 \mathrm{~mL}$ from human plasma samples was obtained and $2.0 \mathrm{~mL}$ acetonitrile was added to remove plasma proteins and the developed microextraction method was applied to supernatant by adjusting the $\mathrm{pH}$ to 3.0 with $0.25 \mathrm{M}$ hydrochloric acid and phosphate buffer solution. Then developed method was applied to supernatant. The results of the plasma sample analysis were calculated from the calibration curve and multiplied by the enrichment factor. 


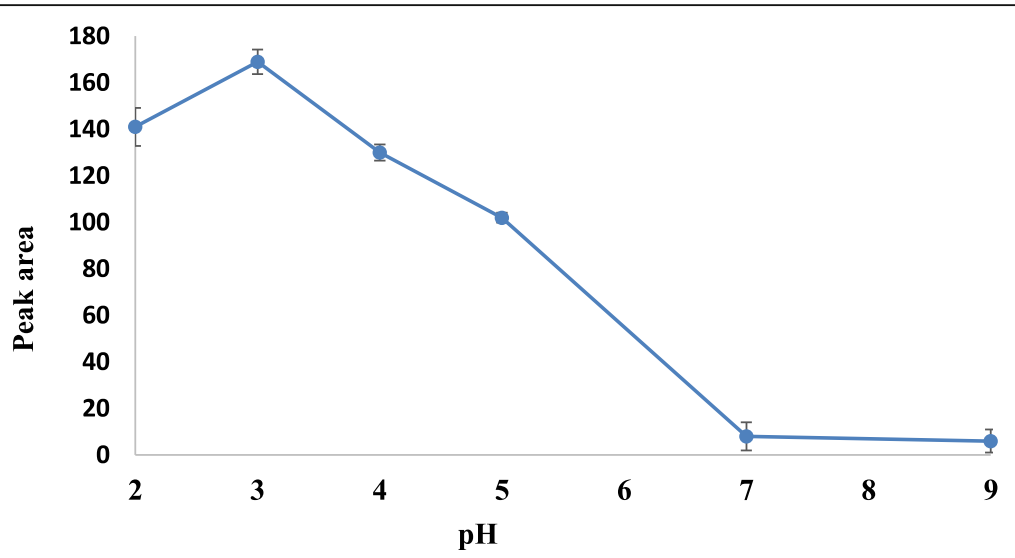

Fig. 2 Effect of $\mathrm{pH}$ on the extraction efficiency of DKT $(n=3)$

\section{Results and discussion}

\section{Effect of $\mathrm{pH}$ on the microextraction efficiency of DKT}

In the extraction methods, the optimum $\mathrm{pH}$ of the sample solution is very important for analytes to passage into the extraction phase from the water phase/ plasma matrix. Thus, the effect of $\mathrm{pH}$ on the recovery of DKT was studied in the range of 2.0-9.0. The peak area results in Fig. 2 show that the maximum recovery for DKT is obtained at $\mathrm{pH}$ 3.0. It can be explained as follows: formation of reverse micelle coacervates occurs from protonated decanoic acid $(\mathrm{pKa}=4.8 \pm 0.2)$; hence, maximum extraction efficiency is expected to be below $\mathrm{pH}$ 4.0. Moreover, pKa value of the DKT is 4.55, for extraction of the DKT from aqueous phase to DA phase, must be nonionic form of DKT; hence, $\mathrm{pH}$ of extraction medium must be lower than 4.55. The procedure was carried out $\mathrm{pH} 3.0$ for the further experiments.
Effect of decanoic acid amount on the microextraction efficiency of DKT

The major components of the reverse micelle coacervates are DA and THF. Therefore, the amount in the colloidal solution mainly affects both the volume of extractant and the extraction efficiency of DKT. Hence, the amount of DA has a significant effect on the extraction DKT from plasma samples. For this purpose, we studied the amount of DA with range of 50-300 mg (Fig. 3). As the amount of decanoic acid added to the aqueous phase increased up to $200 \mathrm{mg}$, the micelle coacervate volume and consequently the extraction efficiency increased. However addition of DA more than $200 \mathrm{mg}$ caused a decrease in extraction efficiency of DKT. Hence, we chose $200 \mathrm{mg}$ of DA as optimum value for the subsequent experiments.

The SEM images of micelles of decanoic acid are examined; it is seen that nano- and molecular-sized

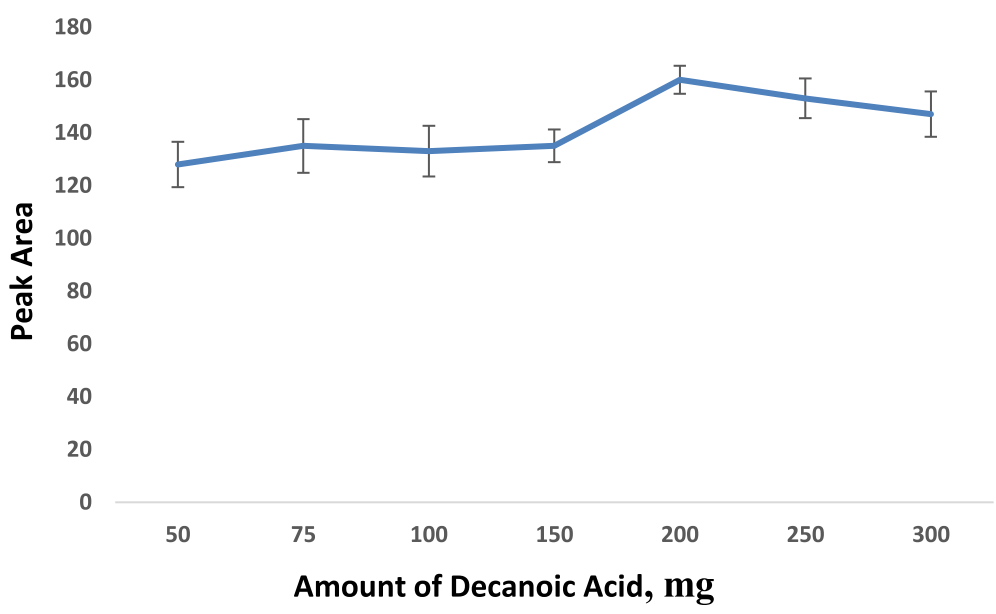

Fig. 3 Effect of DA amount on the extraction efficiency of DKT $(n=3)$ 

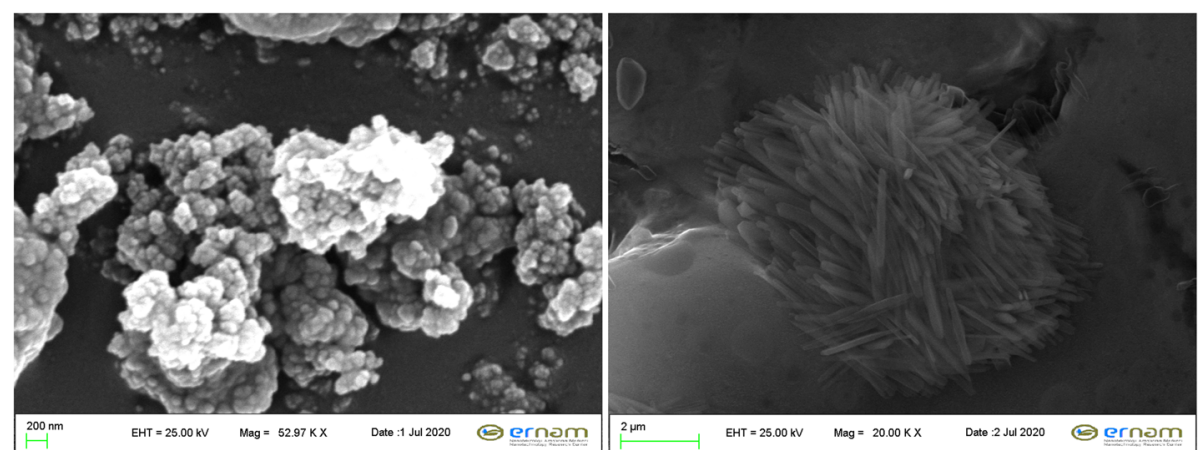

Fig. 4 Scanning electron micrograph of the prepared from decanoic acid/THF (200 mg/600 $\mu \mathrm{L})$ at pH $3.0(10 \mathrm{mM})$. Length of the bars are 200 $\mathrm{nm}$ and $2 \mu \mathrm{m}$ respectively.

micelles are formed in sample solution. The images of micelles are presented in Fig. 4. The obtained SEM images are suitable according the research by Namani and Walde (2005).

\section{Effect of THF volume on the microextraction efficiency of} DKT

THF acts as a dispersing solvent and causes selfassembly of decanoic acid, which is composed of reversed micelles. The volume of THF greatly influences both the volume of extractant and the extraction efficiency in the cloudy solution. To examine the effect of the volume of THF, the range of 300-1000 $\mu \mathrm{L}$ THF volume was studied. The optimum volume of THF was determined to ensure better micelle formation, better dispersion, and quantitative recovery of DKT (Fig. 5) For the extraction method, $600 \mu \mathrm{L}$ of THF was selected, and this volume was used in subsequent studies.
Effect of sonication time on the microextraction efficiency of DKT

The interactions of analytes in aqueous and extraction phases are increased with basic laboratory equipment such as ultrasonic baths, vortex, etc. The ultrasonic waves lead to micro or nano-sized tiny reverse micelle coacervates and extractor droplets (cloudy solution) in sample media. Hence, the equilibrium state is quickly completed and as a result, high-extraction yield is obtained.

The optimum sonication time for microextraction procedure was investigated different time at the range of 1$10 \mathrm{~min}$. As shown in Fig. 6, the obtained results for 7 min sonication are enough to obtain quantitative extraction efficiency for DKT.

\section{Analytical performance}

The analytical performance including limit of detection (LOD), limit of quantification (LOQ), intraday relative

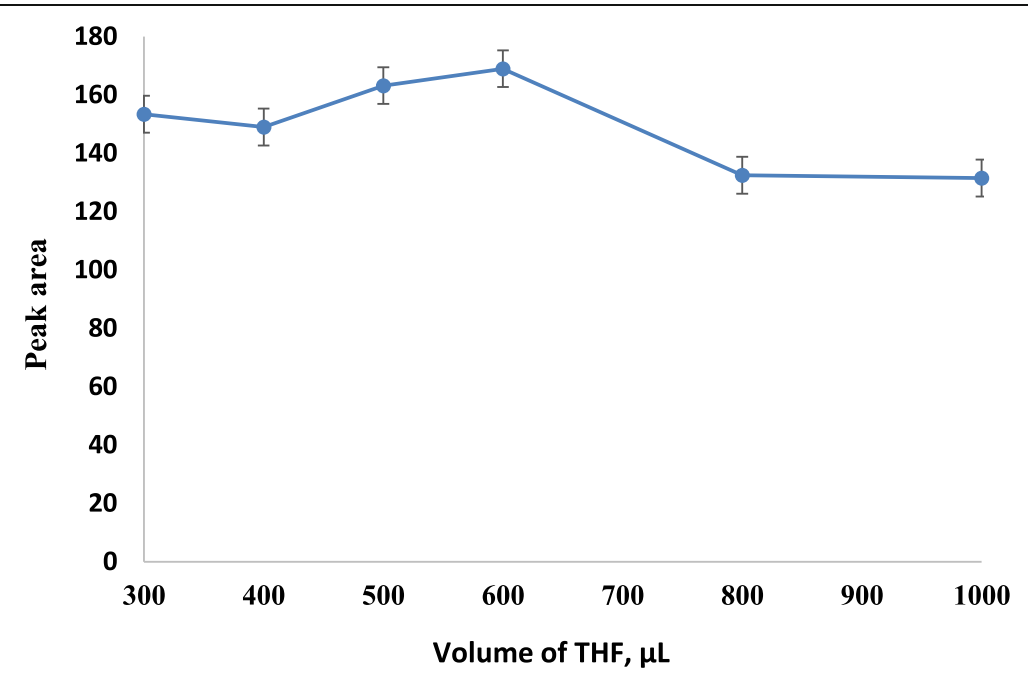

Fig. 5 Effect of THF volume on the extraction efficiency of DKT $(n=3)$ 


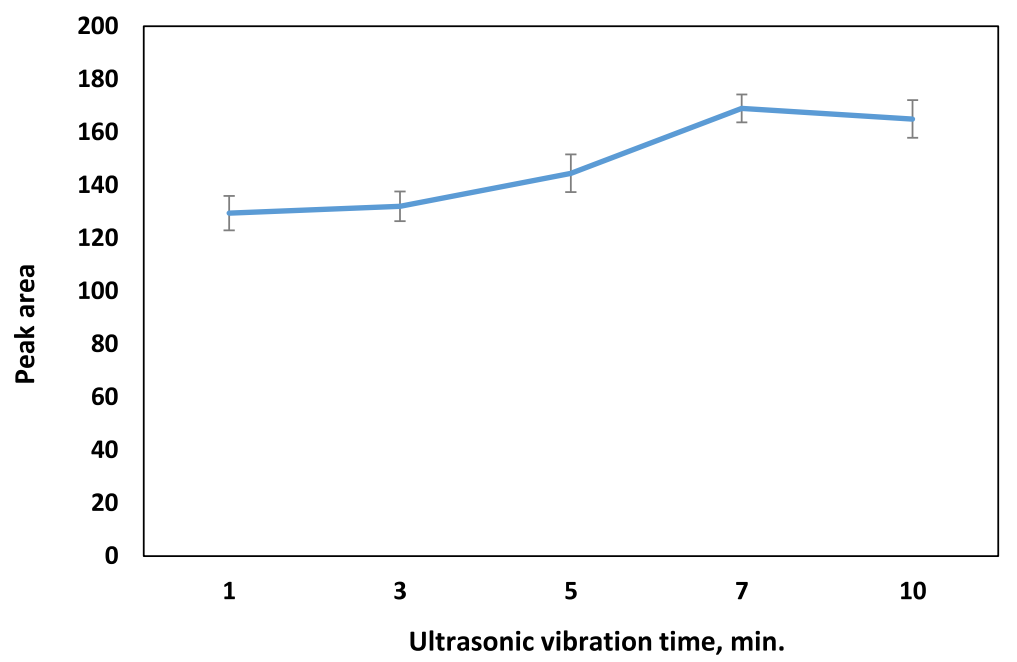

Fig. 6 Effect of ultrasonic vibration time on the extraction efficiency of DKT $(n=3)$

standard deviation and interday relative standard deviation values (RSD, \%) were summarized in Table 1 . The LOD and LOQ were calculated according to The International Council for Harmonisation (ICH) of Technical Requirements for Pharmaceuticals for Human Use Harmonised tripartite guideline that validate analytical procedures. Calculation of LOD and LOQ was based on the standard deviation of the response and the slope of calibration curve. The intraday RSD \% and interday RSD $\%$ values were calculated to determine the precision of the method by using 10 model solutions that contained $0.5 \mu \mathrm{g} \mathrm{mL}{ }^{-1}$ of DKT. For the plasma samples, the LOD and the LOQ of developed method were calculated as 12.8 and $38.8 \mathrm{ng} \mathrm{mL}^{-1}$, respectively. The intraday and interday precision was observed $1.7 \%$ and $3.9 \%$, respectively. The linearity was established across the 50-2000 $\mathrm{ng} / \mathrm{mL}$ concentrations range and the coefficient of determination $\left(r^{2}\right)$ of $\geq 0.999$.

Table 1 Analytical performances of the proposed method at model sample solution and plasma matrix

\begin{tabular}{|c|c|c|c|}
\hline \multicolumn{2}{|c|}{ Model sample solution } & \multicolumn{2}{|l|}{ Plasma sample } \\
\hline Parameter & Value & Parameter & Value \\
\hline $\mathrm{LDA}, \mu \mathrm{g} / \mathrm{mL}$ & $0.01-10.00$ & $\mathrm{LDA}, \mu \mathrm{g} / \mathrm{mL}$ & $0.05-2.00$ \\
\hline $\begin{array}{l}\text { Intraday precision, } \\
\% \text { RSD }(n=6)\end{array}$ & 1.2 & $\begin{array}{l}\text { Intraday precision, } \\
\% \operatorname{RSD}(n=6)\end{array}$ & 1.7 \\
\hline $\begin{array}{l}\text { Interday precision, } \\
\% \operatorname{RSD}(n=6)\end{array}$ & 2.6 & $\begin{array}{l}\text { Interday precision, } \\
\% \operatorname{RSD}(n=6)\end{array}$ & 3.9 \\
\hline$r^{2}$ & 0.9999 & $r^{2}$ & 0.9996 \\
\hline $\mathrm{LOD}, \mathrm{ng} / \mathrm{mL}$ & 0.8 & $\mathrm{LOD}, \mathrm{ng} / \mathrm{mL}$ & 12.8 \\
\hline $\mathrm{LOQ}, \mathrm{ng} / \mathrm{mL}$ & 2.4 & $\mathrm{LOQ}, \mathrm{ng} / \mathrm{mL}$ & 38.8 \\
\hline $\mathrm{EF}$ & 20 & $\mathrm{EF}$ & 2 \\
\hline
\end{tabular}

Accuracy and application of coacervative microextraction method

Accuracy of the developed coacervative microextraction method was proved by addition-recovery experiments for a whole-human plasma sample. Initially, blood plasma samples were divided into 4 portions per $1 \mathrm{~mL}$ aliquots; one aliquot was retained to provide a negativecontrol sample, while three aliquots were spiked with different amount of DKT per milliliter of plasma. Different amounts of dexketoprofen were added to plasma sample, and the developed coacervative microextraction method was applied these samples. The obtained results given in Table 2 showed that quantitative recoveries (97-100\%) were obtained for plasma sample. The results proved that our method is applicable for accurate, rapid and sensitive analysis of DKT in plasma samples.

The changes in the concentration of DKT in the plasma of the male and female patients were analyzed by using the developed method. For this purpose, blood samples taken at different time periods from volunteer patients (a 23-year-old male and a 29-year-old female) that use $25 \mathrm{mg}$ of DKT and different drugs and were subjected to our coacervative microextraction method.

Table 2 Application of the coacervative microextraction method to plasma that spiked DKT $(n=5)$

\begin{tabular}{llll}
\hline Sample & Spiked level, $\boldsymbol{\mu g} / \mathbf{m L}$ & Found, $\boldsymbol{\mu g} / \mathbf{m L}$ & Recovery, $\%$ \\
\hline \multirow{2}{*}{ Human plasma } & 0.00 & $\mathrm{BDL}$ & - \\
& 0.75 & $0.73 \pm 0.02^{\mathrm{a}}$ & $97 \pm 3$ \\
& 1.00 & $0.98 \pm 0.03$ & $98 \pm 3$ \\
& 1.50 & $1.50 \pm 0.06$ & $100 \pm 4$ \\
\hline
\end{tabular}

$B D L$ below detection limits

${ }^{\mathrm{a}}$ Mean \pm standard deviation 


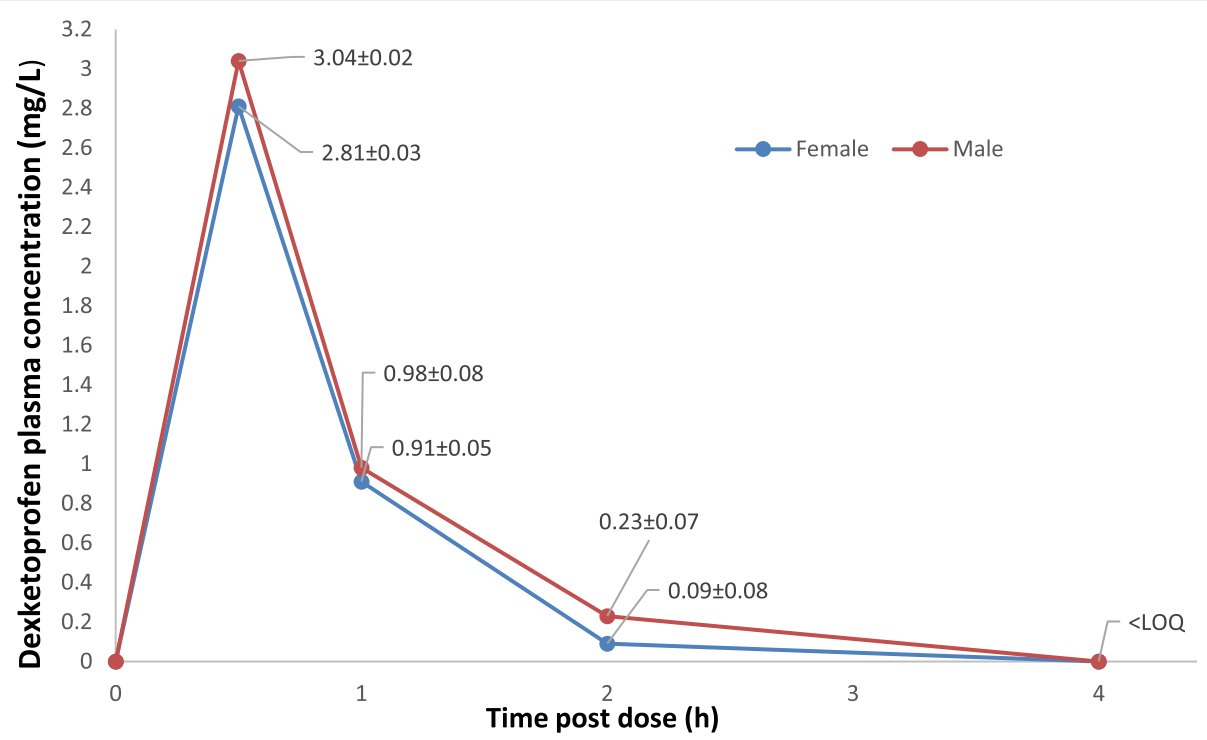

Fig. 7 Mean dexketoprofen concentrations in female and male plasma samples after application of single doses $37 \mathrm{mg}$ of dexketoprofen trometamol corresponding to $25 \mathrm{mg}$ of dexketoprofen). ${ }^{*}<\mathrm{LOQ}$ : under the limit of quantification of the proposed method) $(n=3)$

Then, the samples were analyzed with HPLC-DAD. Changes in the DKT concentration in the plasma samples are presented Fig. 7. The results showed that DKT concentration in plasma samples reached to maximum in 30 min, then decreased quickly and came to the point of exhaustion after $4 \mathrm{~h}$ with daily activities. The clinical study by Barbanoj et al. Barbanoj et al. 1998) was presented that the mean plasma dexketoprofen concentrations after a single oral dose of dexketoprofen trometamol $37 \mathrm{mg}$ (corresponding to $25 \mathrm{mg}$ of the acid), in 18 healthy volunteers were determined nearly $3.4 \mathrm{mg} / \mathrm{L}$ concentration of dexketoprofen. The results of second clinical search reported that the mean plasma dexketoprofen concentrations after a single oral dose of dexketoprofen $25 \mathrm{mg} \mathrm{S}(+)$ in 24 healthy volunteers found $3.10 \pm 1.04 \mathrm{mg} / \mathrm{L}$ (Gich et al. 1995).
The results of proposed method are suitable in literature according to mean plasma concentration.

The developed liquid phase microextraction method prior to HPLC-DAD analysis provided important advantages for the extraction of dexketoprofen in human plasma samples. The chromatographic analysis of plasma samples is shown in Fig. 8. The plasma samples that extracted our proposed method analyzed by HPLC-DAD and chromatographic analysis were completed in $7 \mathrm{~min}$.

\section{Conclusions}

The developed reverse micelle-based coacervate liquid phase microextraction method prior to HPLC-DAD analysis provided an important strategy for the extraction of dexketoprofen in human plasma samples. The formation of nano- and micro-sized reverse micelle-

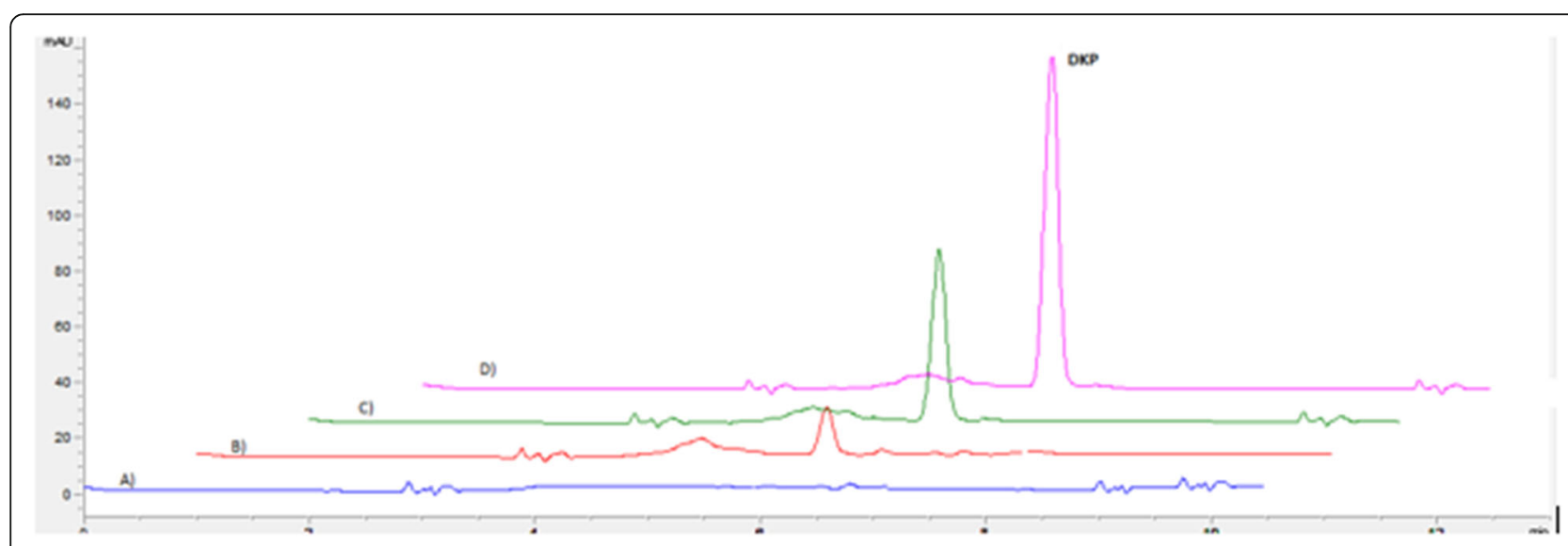

Fig. 8 The chromatographic analysis of plasma samples: A was the chromatogram of blank plasma sample; $B, C$, and D were the chromatogram of plasma samples that contains $0.25,0.5$, and $1.0 \mu \mathrm{g} \mathrm{mL} \mathrm{L}^{-1}$ DKP respectively 
Table 3 Comparison of the developed method with other extraction techniques in literature studies

\begin{tabular}{llllll}
\hline Sample & Sample preparation & Instrument & $\begin{array}{l}\text { LOQ } \\
\mathbf{( n g / m L})\end{array}$ & \% RSD & Ref. \\
\hline Plasma & Direct injection & HPLC & 250.0 & 3.1 & Oda et al. 1991 \\
Plasma & LLE & HPLC & 500.0 & 7.4 & Palylyk and Jamali 1991 \\
Plasma & Direct injection & HPLC & 5000.0 & 1.4 & Oda et al. 1992 \\
Plasma & SPE & HPLC & 200.0 & 7.0 & Eichhold et al. 2000 \\
Plasma & SPE & LC-MS-MS & 0.05 & 7.4 & Carr et al. 1995 \\
Urine & SPE & HPLC & 70.0 & 12.1 & Grubb et al. 1996 \\
Serum & SPE & HPLC & 25.0 & 5.2 & Ameyibor and Stewart 1998 \\
Plasma & Reverse micelle-based coacervate liquid phase microextraction & HPLC & 38.8 & 3.9 & This work \\
\hline
\end{tabular}

based coacervate by ultrasonic vibration leads to the high-extraction efficiency for dexketoprofen. The most important feature of this method is that the changes in the concentration of dexketoprofen in the human plasma samples can be successfully monitored. The method is an environmentally friendly method because it does not require too much organic solvent. The amounts of THF $(600 \mu \mathrm{L})$ and decanoic acid (200 mg) used to create the reverse micelle-based coacervates are very low. Because the extraction solvent does not need to be evaporated, direct extraction solvent analysis (at the microliter level) can be done by HPLC-DAD. Based on these advantages, this developed combination method consist of reverse micellebased coacervate liquid phase microextraction, and HPLC-DAD analysis steps can be used as a practical and simple routine analysis method for monitoring of dexketoprofen in human plasma samples. As can be seen, the proposed method is comparable to other reported methods in which HPLC was applied as the determination and extraction method for dexketoprofen from human plasma according to Table 3 .

\section{Abbreviations}

DKT: Dexketoprofen; HPLC-DAD: High-performance liquid chromatography with photodiode-array detection; DA: Decanoic acid:; EF: Enrichment Factor; THF: Tetrahydrofuran; LDA: Linear dynamic range; LOD: Limit of detection; LOQ: Limit of quantification; RSD: Relative standard deviation; NSAIDs: Nonsteroidal anti-inflammatory drugs; LLE: Liquid-liquid extraction; SPE: Solid phase extraction; LPME: Liquid phase microextraction; ICH: The International Council for Harmonisation; LC-MS-MS: Liquid chromatography- tandem mass spectrometry

\section{Acknowledgements}

The research project has been proved by Erciyes University Clinical Research's Ethics.

\section{Authors' contributions}

All authors have equal contribution to this research work. All authors read and approved the final manuscript.

\section{Funding}

This work has been supported by Erciyes University Scientific Research Projects Coordination Unit with research project TDK-2016-6823.
Availability of data and materials

Not applicable

\section{Competing interests}

The authors declare that they have no competing interests.

\section{Author details}

${ }^{1}$ Faculty of Pharmacy, Deparment of Analytical Chemistry, Erciyes University, Kayseri 38039, Turkey. ${ }^{2}$ Nanotechnology Research Center, Erciyes University, Kayseri 38039, Turkey. ${ }^{3}$ Technology Research \& Application Center (TAUM),

Erciyes University, 38039 Kayseri, Turkey.

Received: 21 April 2020 Accepted: 27 November 2020

Published online: 09 December 2020

\section{References}

Abolu-Enein HY, Dal AG, Tuncel M. A validated method development for ketoprofen by a flow-injection analysis with UV-detection and its application to pharmaceutical formulations. II Farmaco. 2003;58(6):419-22. https://doi. org/10.1016/S0014-827X(03)00061-2.

Ameyibor E, Stewart JT. HPLC determination of ketoprofen enantiomers in human serum using a nonporous octadecylsilane 1.5 microns column with hydroxypropyl beta-cyclodextrin as mobile phase additive. J Pharm Biomed Anal. 1998;17:83-8. https://doi.org/10.1016/S0731-7085(97)00161-1.

Armenta S, Garrigues S, de la Guardia M. Green analytical chemistry. Trends Anal Chem. 2008;27:497-511. https://doi.org/10.1016/j.trac.2008.05.003.

Ballesteros-Gómez A, Rubio S. Environment-responsive alkanol-based supramolecular solvents: Characterization and potential as restricted access property and mixed-mode extractants. Anal Chem. 2012;84:342-9. https://doi.org/10.1021/ac2026207.

Ballesteros-Gómez A, Sicilia MD, Rubio S. Supramolecular solvents in the extraction of organic compounds. Anal Chim Acta. 2010;677:108-30. https://doi.org/10.1016/j.aca.2010.07.027.

Barbanoj MD, Gich I, Artigas R, Tost D, Moros C, Antonjian RM, Garcia ML, Mauleon D. Pharmacokinetics of dexketoprofen trometamol in healthy volunteers after single and repeated oral doses. J of Clinic Pharm. 1998; 38(12):33-40.

Bhusari VK, Dhaneshwar SR. Application of a stability-indicating tlc method for the quantitative determination of dexketoprofen trometamol in pharmaceutical dosage forms. J Liq Chromatogr Relat Technol. 2011;34:260620. https://doi.org/10.1080/10826076.2011.593071.

Buffum M, Buffum JC. Nonsteroidal anti-inflammatory drugs in the elderly. Pain Manag Nurs. 2000;1:40-50. https://doi.org/10.1053/jpmn.2000.7779.

Carr RA, Caillé G, Ngoc AH, Foster RT. Stereospecific high-performance liquid chromatography assay of ketoprofen in human plasma and urine. J Chromatogr B Biomed Appl. 1995;668:175-81. https://doi.org/10.1016/03784347(95)00070-y.

Choudhari VP, Chate SG, Bharande PD, Sharma SN. Spectrophotometric simultaneous determination of dexketoprofen and thiocholchicoside in combined tablet dosage form by absorbance corrected method and first order derivative method. Der Pharma Chem. 2012;4:842-6.

Dvořák J, Hájková R, Matysová L, Nováková L, Koupparis MA, Solich P. Simultaneous HPLC determination of ketoprofen and its degradation 
products in the presence of preservatives in pharmaceuticals. J Pharm Biomed Anal. 2004;36:625-9. https://doi.org/10.1016/j.jpba.2004.07.018.

Eichhold TH, Bailey RE, Tanguay SL, Steven H, Hoke II. Determination of (R)- and (S)-ketoprofen in human plasma by liquid chromatography/tandem mass spectrometry following automated solid-phase extraction in the 96-well format. J Mass Spectrum. 2000;35:504-11. https://doi.org/10.1002/(SICI)10969888(200004)35:4<504::AID-JMS958>3.0.CO;2-L.

Esparza-Villalpando V, Pozos-Guillén A, Masuoka-Ito D, Gaitán-Fonseca C, Chavarría-Bolaños D. Analgesic efficacy of preoperative dexketoprofen trometamol: a systematic review and meta-analysis. Drug Dev Res. 2018;79: 47-57. https://doi.org/10.1002/ddr.21419.

Feizi N, Yamini Y, Moradi M, Karimi M, Salamat Q, Amanzadeh H. A new generation of nano-structured supramolecular solvents based on propanol/ gemini surfactant for liquid phase microextraction. Anal Chim Acta. 2017;953: 1-9. https://doi.org/10.1016/j.aca.2016.11.007.

Gich I, Barbanoj MJ, Artigas R, et al. (1995) New fast-onset oral formulation of desketoprofen [abstract]. 6th Interscience World Conference on Inflammation, Antirheumatics, Analgesics and Immunomodulators (INWIN = 95); 1995 Mar 28-30; Geneva.

Grubb NB, Rudy DW, Hall SD. Stereoselective high-performance liquid chromatography analysis of ketoprofen and its acyl glucuronides in chronic renal insufficiency. J Chromatogr B Biomed Appl. 1996;678:237-44. https:// doi.org/10.1016/0378-4347(95)00517-x.

Haq N, Iqbal M, Alanazi FK, Alsarra IA, Shakeel F. Applying green analytical chemistry for rapid analysis of drugs: Adding health to pharmaceutical industry. Arab J Chem. 2017;10:777-85. https://doi.org/10.1016/j.arabjc.2012. 12.004 .

Kole PL, Venkatesh G, Kotecha J, Sheshala R. Recent advances in sample preparation techniques for effective bioanalytical methods. Biomed Chromatogr. 2011;25:199-217. https://doi.org/10.1002/bmc.1560.

López-Jiménez FJ, Ballesteros-Gómez A, Rubio S. Determination of polycyclic aromatic hydrocarbons (PAH4) in food by vesicular supramolecular solventbased microextraction and LC-fluorescence detection. Food Chem. 2014;143: 341-7. https://doi.org/10.1016/j.foodchem.2013.07.136.

Mabrouk MM, Hammad SF, El-fatatry HM, El-malla SF. Spectroscopic methods for determination of dexketoprofen trometamol and tramadol hcl. Pharm Analysis Quality Assurance. 2014;4:276-82.

Marco-Urrea E, Pérez-Trujillo M, Cruz-Morató C, Caminal G, Vicent T. White-rot fungus-mediated degradation of the analgesic ketoprofen and identification of intermediates by HPLC-DAD-MS and NMR. Chemosphere. 2010;78:474-81. https://doi.org/10.1016/j.chemosphere.2009.10.009.

Miranda HF, Sierralta F, Aranda N, Noriega V, Prieto JC. Pharmacological profile of dexketoprofen in orofacial pain. Pharmacol Rep. 2016;68:1111-4. https://doi. org/10.1016/j.pharep.2016.06.015.

Moein MM, El Beqqali A, Abdel-Rehim M. Bioanalytical method development and validation: Critical concepts and strategies. J Chromatogr B Anal Technol Biomed Life Sci. 2017;1043:3-11. https://doi.org/10.1016/j.jchromb.2016.09.028.

Mohamed HM. Green, environment-friendly, analytical tools give insights in pharmaceuticals and cosmetics analysis. Trends Anal Chem. 2015;66:176-92. https://doi.org/10.1016/j.trac.2014.11.010.

Namani T, Walde P. From decanoate micelles to decanoic acid/ dodecylbenzenesulfonate vesicles. Langmuir. 2005;21:6210-9. https:/doi.org/ 10.1021/la047028z

Oda Y, Asakawa N, Abe S, Yoshida Y, Sato T. Avidin protein-conjugated column for injection analysis of drug enantiomers in plasma by high-performance liquid chromatography. J Chromtogr Biomed Appl. 1991;570:133-41. https://doi.org/10.1016/0378-4347(91)80478-U.

Oda Y, Asakawa N, Yoshida Y, Sato T. On-line determination and resolution of the enantiomers of ketoprofen in plasma using couple achiral-chiral highperformance liquid chromatography. J Pharm Biomed Anal. 1992;10:81-7. https://doi.org/10.1016/0731-7085(92)80015-F.

Palylyk E, Jamali F. Simultaneous determination of ketoprofen enantiomers and probenecid in plasma and urine by high-performance liquid chromatography. J Chromtogr Biomed Appl. 1991;568:187-96. https://doi. org/10.1016/0378-4347(91)80352-D.

Tettey-Amlalo RNO, Kanfer I. Rapid UPLC-MS/MS method for the determination of ketoprofen in human dermal microdialysis samples. J Pharm Biomed Anal. 2009;50:580-6. https://doi.org/10.1016/j.jpba.2008.09.051.

Vaghela A, Patel A, Vyas A, Patel N. Sample preparation in bioanalysis : a review. Int J Scientific Technol Res. 2016;5:6-10.
Wille K, Noppe H, Verheyden K, Vanden Bussche J, De Wulf E, Van Caeter P, Janssen CR, De Brabander HF, Vanhaecke L. Validation and application of an LC-MS/MS method for the simultaneous quantification of 13 pharmaceuticals in seawater. Anal Bioanal Chem. 2010;397:1797-808. https://doi.org/10.1007/ s00216-010-3702-z.

Wongrakpanich S, Wongrakpanich A, Melhado K, Rangaswami J. A comprehensive review of non-steroidal anti-inflammatory drug use in the elderly. Aging Dis. 2018;9:143-56. https://doi.org/10.14336/AD.2017.0306.

Xue YJ, Billy Akinsanya J, Liu J, Unger SE. A simplified protein precipitation/ mixed-mode cation-exchange solid-phase extraction, followed by highspeed liquid chromatography/mass spectrometry, for the determination of a basic drug in human plasma. Rapid Commun. Mass Spectrom. 2006;20:26608. https://doi.org/10.1002/rcm.2645.

\section{Publisher's Note}

Springer Nature remains neutral with regard to jurisdictional claims in published maps and institutional affiliations.

\section{Submit your manuscript to a SpringerOpen ${ }^{\circ}$ journal and benefit from:}

- Convenient online submission

- Rigorous peer review

- Open access: articles freely available online

High visibility within the field

- Retaining the copyright to your article

Submit your next manuscript at $\boldsymbol{\nabla}$ springeropen.com 